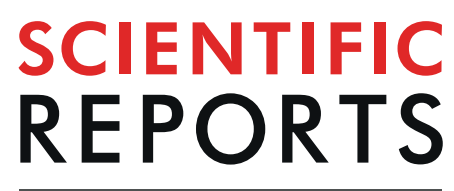

natureresearch

\title{
OPEN
}

Published online: 27 February 2020

\section{Publisher Correction: Optimal Mass Transport with Lagrangian Workflow Reveals Advective and Diffusion Driven Solute Transport in the Glymphatic System}

Sunil Koundal, Rena Elkin, Saad Nadeem, Yuechuan Xue, Stefan Constantinou, Simon Sanggaard, Xiaodan Liu, Brittany Monte, Feng Xu, William Van Nostrand, Maiken Nedergaard, Hedok Lee, Joanna Wardlaw $(\mathbb{D}$, Helene Benveniste \& Allen Tannenbaum

Correction to: Scientific Reports https://doi.org/10.1038/s41598-020-59045-9, published online 06 February 2020

The original version of this Article contained a typographical error in the spelling of the author Sunil Koundal, which was incorrectly given as Sunil Kounda. This has now been corrected in the PDF and HTML versions of the Article.

(i) Open Access This article is licensed under a Creative Commons Attribution 4.0 International License, which permits use, sharing, adaptation, distribution and reproduction in any medium or format, as long as you give appropriate credit to the original author(s) and the source, provide a link to the Creative Commons licence, and indicate if changes were made. The images or other third party material in this article are included in the article's Creative Commons licence, unless indicated otherwise in a credit line to the material. If material is not included in the article's Creative Commons licence and your intended use is not permitted by statutory regulation or exceeds the permitted use, you will need to obtain permission directly from the copyright holder. To view a copy of this licence, visit http://creativecommons.org/licenses/by/4.0/.

(C) The Author(s) 2020 